\title{
Improved Wind and Turbulence Measurements Using a Low-Cost 3-D Sonic Anemometer at a Low-Wind Site
}

\author{
Brent M. Bowen ${ }^{*}$
}

\author{
Environmental Protection Department, Lawrence Livermore National Laboratory, Livermore, California, USA
}

\begin{abstract}
A year of data from sonic anemometer and mechanical wind sensors was analyzed and compared at a low-wind site. Results indicate that 15-minute average and peak 1-second wind speeds $(u)$ from the sonic agree well with data derived from a co-located cup anemometer over a wide range of speeds. Wind direction data derived from the sonic also agree closely with those from a wind vane except for very low wind speeds. Values of standard deviation of longitudinal wind speed $\left(\sigma_{u}\right)$ and wind direction fluctuations $\left(\sigma_{\theta}\right)$ from the sonic and mechanical sensors agree well for times with $u>$ $2 \mathrm{~ms}^{-1}$ but show significant differences with lower $u$ values. The most significant differences are associated with the standard deviation of vertical wind fluctuations $\left(\sigma_{w}\right)$ : the co-located vertical propeller anemometer yields values increasingly less than those measured by the sonic anemometer as $u$ decreases from 2.5 approaching $0 \mathrm{~ms}^{-1}$. The combination of $u$ over-estimation and under-estimation of $\sigma_{w}$ from the mechanical sensors at low wind speeds causes considerable underestimation of the standard deviation of vertical wind angle fluctuations $\left(\sigma_{\phi}\right)$, an indicator of vertical dispersion. Calculations of $\sigma_{\phi}$ from sonic anemometer measurements are typically $5^{\circ}$ to $10^{\circ}$ greater than from the mechanical sensors when the mechanical instruments indicate that $\sigma_{\phi}<5^{\circ}$ or so. The errors with the propeller anemometer, cup anemometer and wind vane, caused by their inability to respond to higher frequency (smaller scale) turbulent fluctuations, can therefore lead to large (factors of 2 to 10 or more) errors in both the vertical and horizontal dispersion during stable conditions with light winds. The sonic anemometer clearly provides more accurate and reliable wind data than the mechanical wind sensor with $u<2.5 \mathrm{~ms}^{-1}$.
\end{abstract}

Keywords: Sonic anemometer, turbulence, towers.

\section{INTRODUCTION}

Sonic anemometers measure wind velocity by measuring the effect of the wind on the transit times of ultrasonic acoustic pulses. A sonic temperature can also be derived from the speed of sound. The sonic anemometer is widely recognized as one of the best instruments for measuring and studying atmospheric turbulence. Desirable characteristics of the sonic anemometer include lack of moving parts, linear dynamic response, good directional response, and frequency response limited only by the sound path length. The first sonic anemometers were large and expensive [1], limited to one axis (used primarily to measure vertical turbulence), and developed because there was inadequate instrumentation to measure atmospheric turbulence to support research [2]. Further breakthroughs allowed development of improved and more reliable vertical and three-dimensional (3-D) sonic anemometers used primarily for research.

Inexpensive two-dimensional (2-D) sonic anemometers are becoming more widely used for routine wind monitoring because of their low or no maintenance requirements. Sonic anemometers are also capable of measuring wind and turbulence statistics at very low wind speeds, below starting thresholds of mechanical wind sensors. For example, the

*Address correspondence to this author at the Lawrence Livermore National Laboratory, Environmental Protection Department, TAMM Division, L-629, 7000 East Avenue, Livermore, CA 94550, USA;

E-mail: bbowen@yahoo.com
National Weather Service and Federal Aviation Administration are replacing the cup anemometers and wind vanes that are currently used in the Automated Surface Observing System (ASOS) with 2-D sonic anemometers [3]. The Tennessee Valley Authority has also selected an ultrasonic anemometer to replace the traditional wind vane and anemometer [4]. Until recently, only expensive research sonic anemometers were available for estimating vertical turbulent wind variables in order to estimate vertical dispersion and fluxes of heat, latent heat and momentum. Routine wind and turbulence monitoring by 3-D sonic anemometers is becoming more common as well (e.g., see [5, 6]).

This paper describes the results of comparing horizontal winds and 3-D turbulent statistics measured by mechanical wind sensors with a co-located 3-D sonic anemometer over an entire year. Implications of the measurement differences and the feasibility of using the 3-D sonic anemometer for routine monitoring are discussed.

\section{STUDY DESCRIPTION}

The Terrestrial and Atmospheric Monitoring and Modeling (TAMM) Division of the Environmental Protection Department (EPD) at the Lawrence Livermore National Laboratory (LLNL) is responsible for meteorological monitoring and analysis to support emergency and regulatory dispersion modeling, Laboratory field activities and operations, and special studies. The TAMM Division acquired and installed an inexpensive 3-D sonic anemometer at the $10-\mathrm{m}$ level on one of its meteorological towers to supplement its monitor- 
ing program. Goals include acquiring data to make accurate estimates of evaporation (evaporative heat flux), vertical heat and momentum flux, and improved vertical turbulent fluctuation data. This instrument also serves as a redundant sensor to co-located mechanical sensors at the same height.

This study was made at a 35-m meteorological tower located on the northwest corner of LLNL's Livermore site (Fig. 1). The site is located on the eastern side of the Livermore Valley, about $50 \mathrm{~km}$ east of Oakland, California and at an elevation of $174 \mathrm{~m}$. The site is flat and the terrain slopes up gently toward the southeast at a grade of slightly more than $1 \%$. Annual grasses grow at the site. The closest obstructions include a north-south line of eucalyptus trees about $125 \mathrm{~m}$ to the east, commercial buildings $220 \mathrm{~m}$ to the north and the eastern edge of single family dwellings located $250 \mathrm{~m}$ to the west.

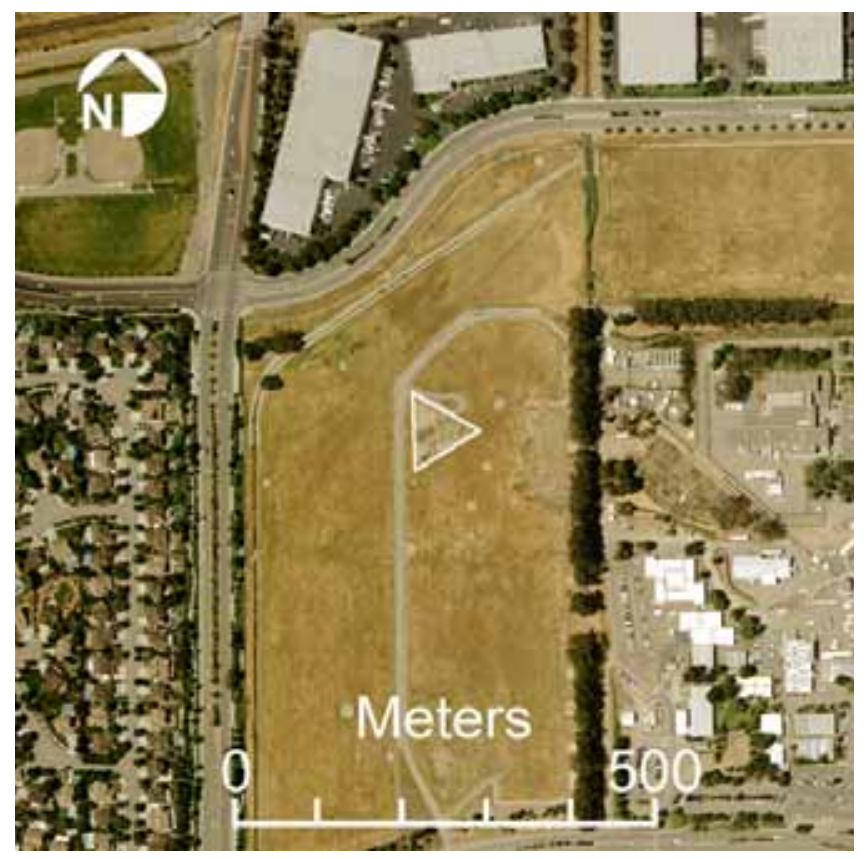

Fig. (1). Aerial photograph of tower (in middle) and surrounding area.

The LLNL Livermore site has an average wind speed of only $2.5 \mathrm{~ms}^{-1}$ and experiences a high frequency of low wind speeds [7]. Wind speeds are less than $1 \mathrm{~ms}^{-1}$ for $27 \%$ of the time and less than $2 \mathrm{~ms}^{-1}$ for $50 \%$ of the time. Sea breezes predominate during the warm season and are largely responsible for the high annual frequency $(\sim 55 \%)$ of winds from the southwest through west sectors. Approximately $13 \%$ of the winds, mostly very light, blow from the east-northeast through east-southeast sectors and are most affected by the line of eucalyptus trees.

The orientation of the sensors on the 10- and 35-m tower booms is shown in Fig. (2). Note that the instrumentation and placement is identical on the two booms except for the sonic anemometer located only on the $10-\mathrm{m}$ boom. The booms are installed toward the west at a distance more than two tower widths away from the open lattice tower to minimize tower effects on measurements. A datalogger (Campbell Scientific $\mathrm{CR} 23 \mathrm{X})$ is connected to and polls all of the instruments at a 1$\mathrm{Hz}$ rate. The datalogger calculates 15-minute averages, stan- dard deviations, and other parameters that are downloaded to a remote server via modem every 15 minutes. Average wind direction is calculated as a vector and average wind speed is calculated as a scalar. The standard deviation of horizontal wind direction fluctuations $\left(\sigma_{\theta}\right)$ is calculated by a single pass method recommended by Yamartino [8]. Data are automatically assured for quality during real-time, visually scanned daily, and thoroughly checked monthly.

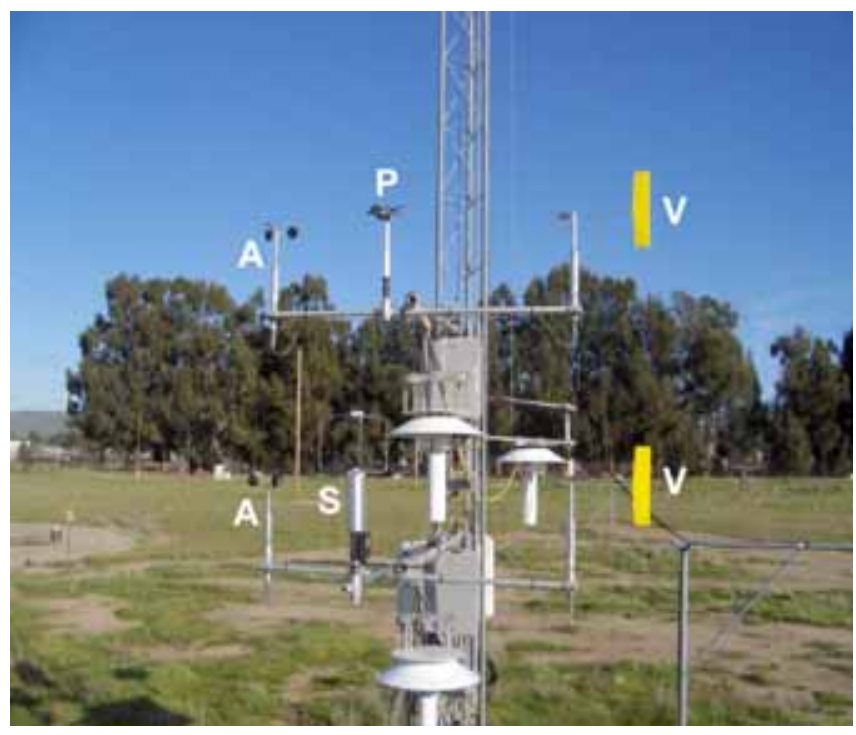

Fig. (2). Wind sensor orientation on 10- and 35-m tower booms. The sonic anemometer (designated as " $\mathrm{S}$ ") is located beyond the cross arm on the lowest level. The cup anemometers (A) and wind vanes (V) are located on opposite sides of the cross arms and the vertical propellers $(\mathrm{P})$ are located in between (the $10-\mathrm{m}$ vertical propeller is obstructed by the upper level aspirated radiation shield).

The mechanical wind sensors used to measure wind direction and speed are the Met One 010C wind vane and 020C 3-cup anemometer. The stated accuracy of the wind vane is $\pm 3^{\circ}$ and the distant constant $(\lambda)$ is less than $0.9 \mathrm{~m}$ (see Table $\mathbf{1}$ for specification summary). The cup anemometer is accurate to within $\pm 1 \%$ at speeds less than $50 \mathrm{~ms}^{-1}$ and $\lambda$ is less than $1.5 \mathrm{~m}$. An R.M. Young propeller anemometer $27106 \mathrm{~T}$ measures the vertical wind speed. The vertical propeller is accurate to within $\pm 1 \%$ within speeds of $\pm 20 \mathrm{~ms}^{-1}$ and $\lambda=2.1 \mathrm{~m}$. Vertical wind speeds are multiplied by a factor of 1.25 by the datalogger in real time as suggested by the manufacturer. The use of the multiplier brings the vertical anemometer output signal to within $\pm 3 \%$ of the cosine response for typical conditions. All sensors have a starting threshold of $0.22 \mathrm{~ms}^{-1}$.

Table 1. Summary of Instrument Specifications

\begin{tabular}{|c|c|c|c|}
\hline Wind Instrument: & Accuracy & $\lambda(\mathbf{m})$ & $\begin{array}{c}\text { Starting Threshold } \\
\left(\mathbf{m s}^{-1}\right)\end{array}$ \\
\hline \hline Wind vane & $\pm 3^{\circ}$ & $<0.9$ & 0.22 \\
\hline Cup anemometer & $\pm 1 \%$ & $<1.5$ & 0.22 \\
\hline Vertical propeller & $\pm 1 \%$ & 2.1 & 0.22 \\
\hline Sonic anemometer & $\begin{array}{c} \pm 1 \% \mathrm{rms}^{-1} \\
\pm 0.05 \mathrm{~ms}^{-1}\end{array}$ & $\sim 0$ & 0.20 \\
\hline
\end{tabular}


An R.M. Young Model 81000 ultrasonic anemometer was used in this study to measure fast-response wind measurements in three dimensions. The sensor has 3 opposing pairs of ultrasonic transducers that are arranged so that measurements are made through a common volume. The stated wind direction accuracy is $\pm 2^{\circ}$ for wind speeds of 1 to $30 \mathrm{~ms}^{-1}$. The wind speed accuracy is $\pm 1 \% \mathrm{rms} \pm 0.05 \mathrm{~ms}^{-1}$ for speeds up to $30 \mathrm{~ms}^{-1}$. The starting threshold during this experiment is the factory set value of $0.2 \mathrm{~ms}^{-1}$ although it can be set to as low as $0.01 \mathrm{~ms}^{-1}$. While the data output frequency from the sonic anemometer is $4 \mathrm{~Hz}$, the effective frequency is reduced to $1 \mathrm{~Hz}$ based on the datalogger polling rate. The sonic anemometer is also able to measure air temperature with a stated accuracy of $\pm 2{ }^{\circ} \mathrm{C}$.

A year (2004) of 15-minute averaged data measured by the sonic and mechanical wind sensors was analyzed and compared. The following variables and derived parameters are routinely monitored and were analyzed in this study: 15minute average and peak 1-second (scalar) wind speed $(u)$, standard deviation of longitudinal wind speed fluctuations $\left(\sigma_{u}\right)$, wind direction $(\theta)$ and the standard deviation of its fluctuations $\left(\sigma_{\theta}\right)$, standard deviation of vertical wind speed $\left(\sigma_{w}\right)$ and wind angle fluctuations $\left(\sigma_{\phi}\right)$, and momentum flux - $\left(\overline{u^{\prime} w}\right)$. Note that the ratio $\sigma_{w} / u$ was used to estimate $\sigma_{\phi}$. The infrequent times when winds blew through the tower toward the sensors (i.e., easterly winds) were removed from the analysis. Finally, about $1 \%$ of the times were removed from the analyses because of a wetting problem on the sonic anemometer probes which caused unrealistically high wind speeds, primarily with vertical and peak wind measurements. Most of the data loss occurred during or after rain with very light winds. [Note that this problem is nearly eliminated with a recent company upgrade of the probes].

\section{RESULTS}

\subsection{Horizontal Wind Variables}

The correlation of sonic- $v s$ cup-derived wind speeds is shown in Fig. (3). The correlation appears excellent throughout the range of wind speeds. The correlation in this study is slightly better than the agreement found in the studies by [3, 5] which compared wind speeds derived from sonic with propeller anemometers. Note that these previous studies used shorter averaging periods of 2 and 5 minutes, respectively. The peak differences in the cup anemometer from the sonic are $+1.0 \mathrm{~ms}^{-1}$ and $-1.2 \mathrm{~ms}^{-1}$, the 5- and 95-percentile values are -0.08 and $0.25 \mathrm{~ms}^{-1}$, respectively, and the standard deviation is $0.11 \mathrm{~ms}^{-1}$. However, scatter is more apparent at wind speeds less than $2.5 \mathrm{~ms}^{-1}$ or so. Fig. (4) analyzes the same data by fractional error and more clearly indicates the increased scatter as well as the bias at low speeds. Note the steady increase in scatter as wind speeds decrease. A bias of high wind speeds from the cup anemometer becomes noticeable at speeds (as measured by the cups) less than about 2.5 $\mathrm{ms}^{-1}$. The cup anemometer measures higher speeds than the sonic does for $93 \%$ of the time when the cup indicates speeds less than or equal to $2 \mathrm{~ms}^{-1}$ and the median bias is $0.13 \mathrm{~ms}^{-1}$. The likely cause of the bias at light wind speeds is the over-speeding by the cup anemometer during variable wind conditions as explained by Wyngaard [9]. While these relatively small errors may be ignored for most users interested in average weather conditions, it will be shown later in the paper that these errors may contribute to large errors in determining widely-used vertical turbulence and dispersion values.

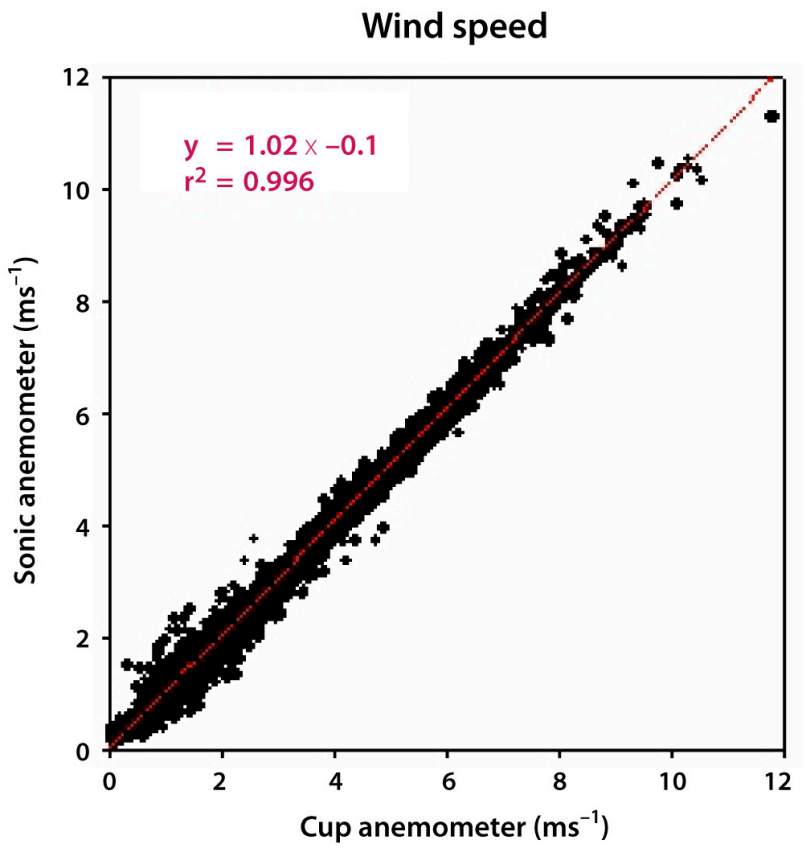

Fig. (3). Regression analysis of 15-minute average wind speeds as measured by cup vs sonic anemometer.

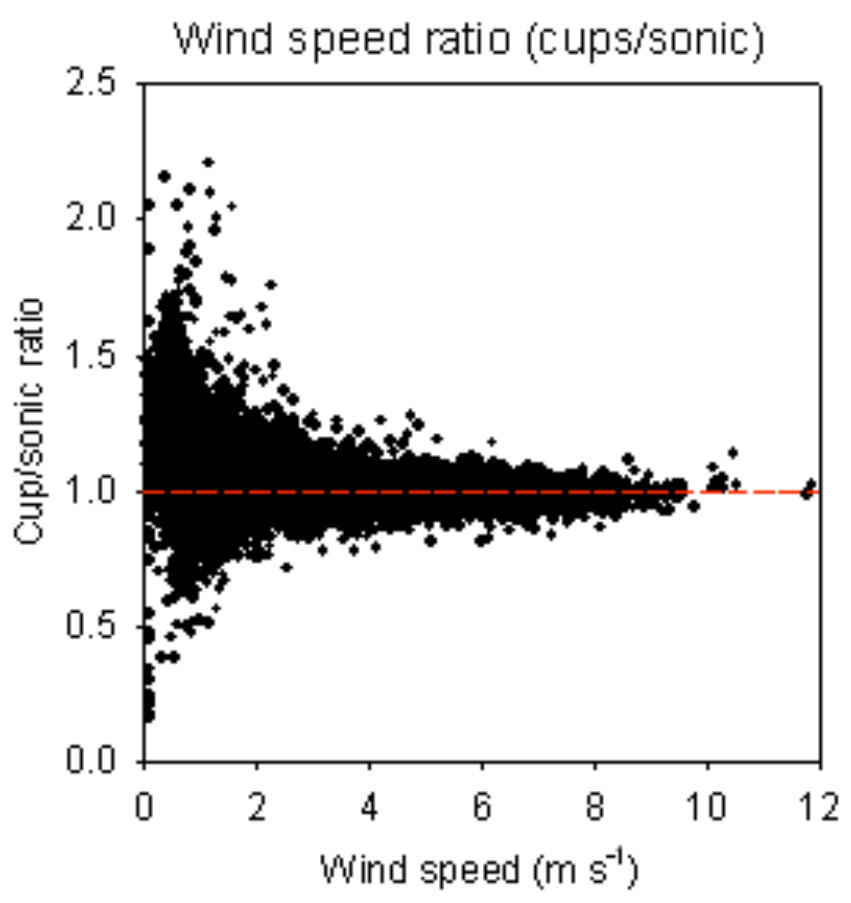

Fig. (4). Ratio of cup/sonic anemometer-derived wind speed as a function of wind speed as measured by the cup anemometer.

The characteristics of both sensors in estimating wind speed are examined further by comparing measured $\sigma_{u}$ values. This variable is also used to estimate dispersion of a puff in the downwind direction. The scatter plot in Fig. (5) 
illustrates that $\sigma_{u}$ values show excellent agreement between the cup and sonic anemometer measurements with $r^{2}=0.98$. The cup anemometer indicates slightly lower $\sigma_{u}$ values $\left(\sim 0.06 \mathrm{~ms}^{-1}\right)$ than from the sonic anemometer for wind speeds greater than $3 \mathrm{~ms}^{-1}$ (not shown). However, the fractional analysis shown in Fig. (6) indicates a similar large bias for $\sigma_{u}$ as with wind speed at speeds less than about $2.5 \mathrm{~ms}^{-1}$. The median cup/sonic $\sigma_{u}$ ratio increases from 0.94 for all wind speeds to 1.00 and 1.08 for speeds less than 2 and $1 \mathrm{~ms}^{-1}$, respectively. The distributions in Figs. (5) and (6) suggest that the cup anemometer yields slightly higher values but large fractional differences of $u$ and $\sigma_{u}$ compared to those measured by the sonic anemometer at low speeds. The bias disappears at speeds above 2 to $2.5 \mathrm{~ms}^{-1}$.

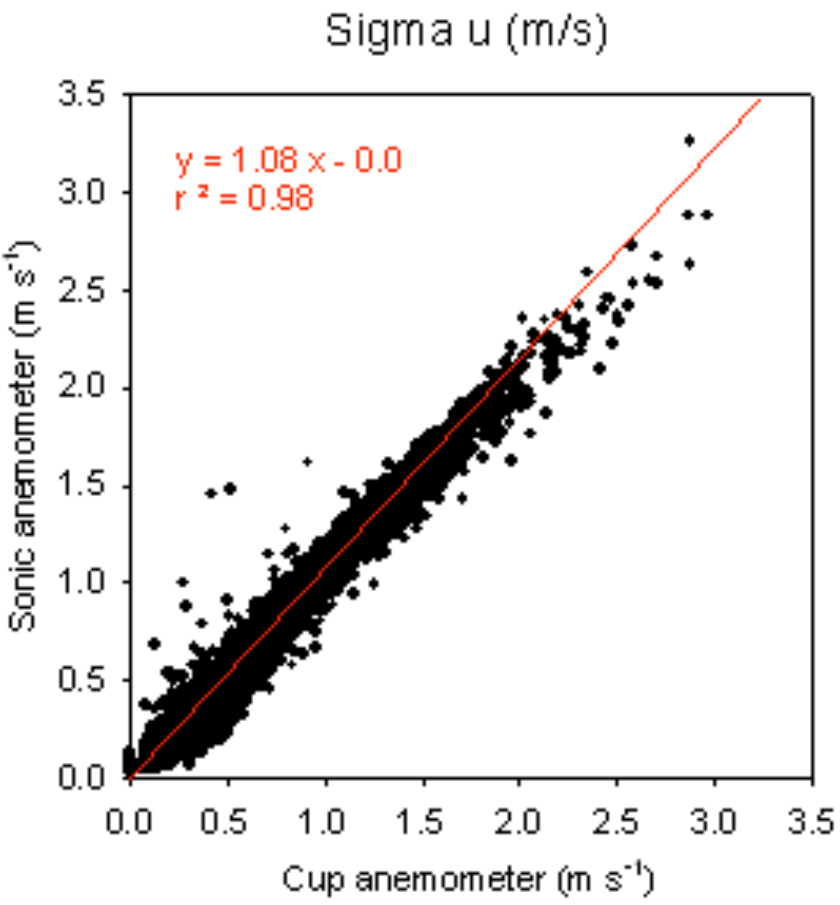

Fig. (5). Regression analysis of 15-minute average $\sigma_{u}$ as measured by cup vs sonic anemometers.

Peak wind gusts (1-sec) were also compared between the cup and sonic anemometer and a scatter plot is shown in Fig. (7). The correlation is excellent and virtually the same as for average wind speed. The median cup/sonic ratio of wind gusts is 1.02 for all speeds and increases to 1.07 and 1.13 for wind speed values less than 2 and $1 \mathrm{~ms}^{-1}$, respectively. The plot suggests that the cup anemometer indicates slightly higher speeds than the sonic at speeds greater than $17 \mathrm{~ms}^{-1}$ as indicated by the cup anemometer. The relatively small sample in this study does not agree with a study by Gilhousen [10] that indicated a 2-D sonic anemometers reported wind speeds about $10 \%$ higher than from vane and propeller anemometers at two coastal and one buoy site with wind speeds $>15 \mathrm{~ms}^{-1}$.

An analysis comparing wind direction measured by the co-located wind sensors was also made. A systematic difference of almost $5^{\circ}$ for all directions was observed and attributed to slight orientation error of either or both of the

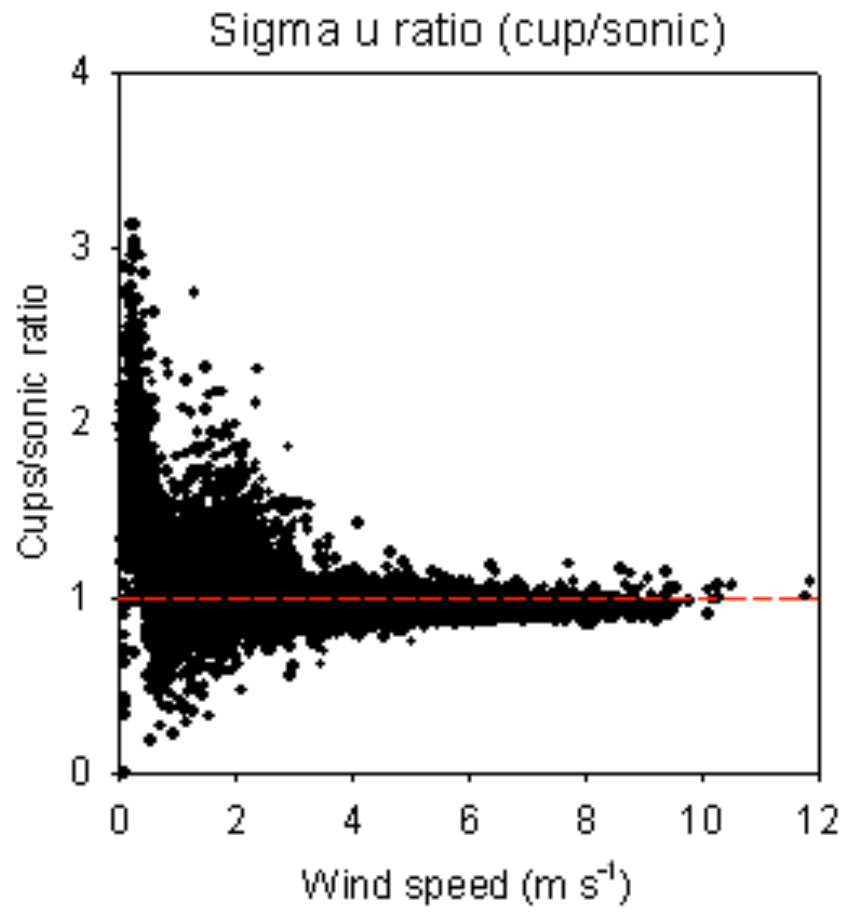

Fig. (6). Ratio of cup/sonic anemometer-derived $\sigma_{u}$ as a function of wind speed as measured by the cup anemometer.

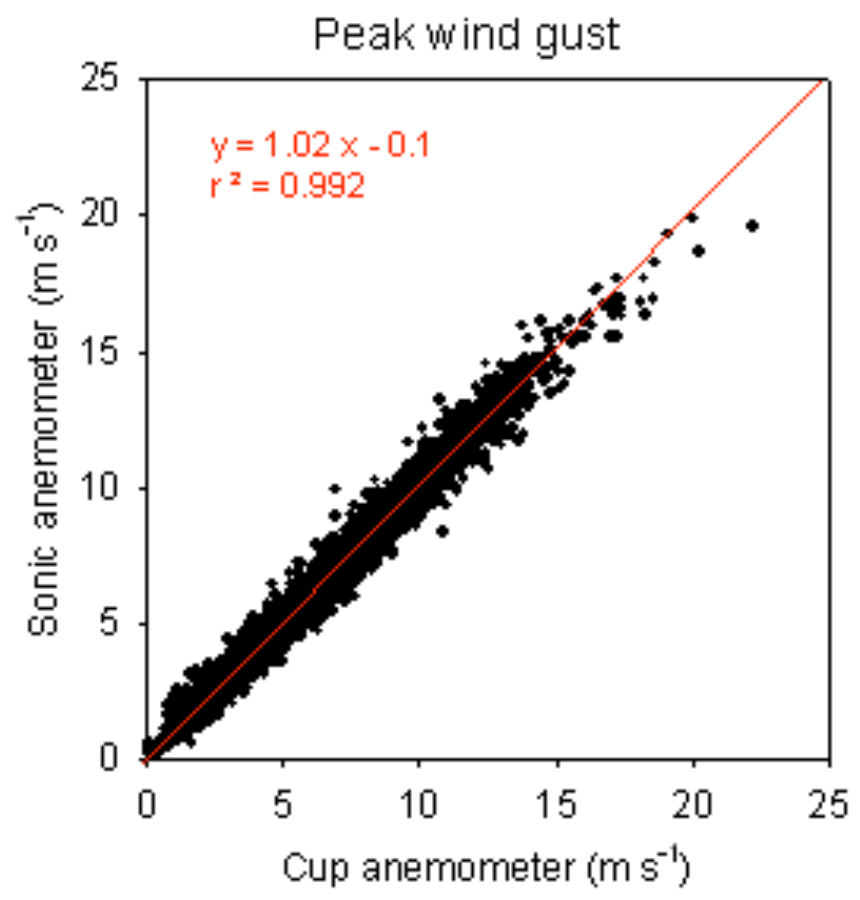

Fig. (7). Regression analysis of peak wind gusts as measured by cup $v s$ sonic anemometer.

sensors. The difference was corrected and the fractional analysis is shown in Fig. (8). Note the excellent agreement and the noticeable increase in scatter at wind speeds less than $2 \mathrm{~ms}^{-1}$ as measured by the cup anemometer. While the slower response of the wind vane undoubtedly causes errors with light wind speeds below $1 \mathrm{~ms}^{-1}$, measured wind directions may not be meaningful at these wind speeds. Anfossi et al. [11] 


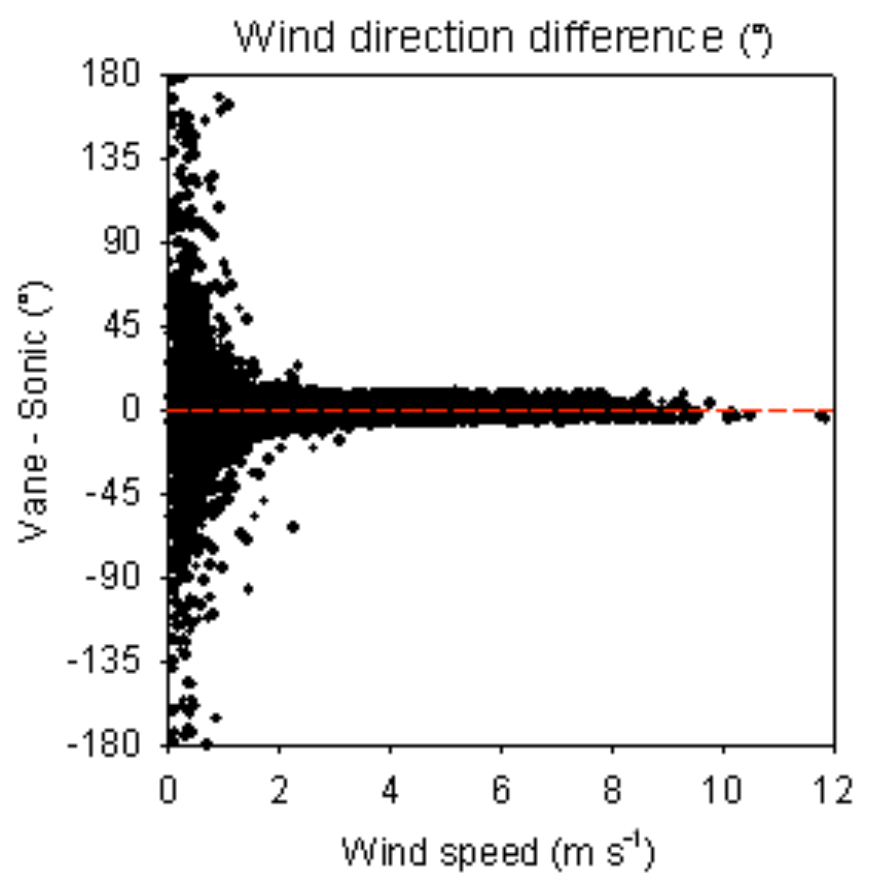

Fig. (8). Difference in vane- and sonic- derived wind direction as a function of wind speed as measured by the cup anemometer.

point out that meandering (low frequency horizontal wind oscillations) begins to prevail when winds decrease below a certain level (1-2 $\left.\mathrm{ms}^{-1}\right)$ and that it becomes difficult to define a precise wind direction and to predict airborne dispersion. Deaves and Lines [12] suggest a lower limiting wind speed that ranges from $0.5 \mathrm{~ms}^{-1}$ in stable and neutral conditions to $1.2 \mathrm{~ms}^{-1}$ in unstable conditions. Wind direction differences were within $\pm 7^{\circ}$ and $\pm 5^{\circ} 90 \%$ and $80 \%$ of the time, respectively. Wind direction differences exceeded $13^{\circ}$ and $23^{\circ}$ for $20 \%$ and $10 \%$ of the time, respectively, when wind speeds were less than $1 \mathrm{~ms}^{-1}$.

Values of $\sigma_{\theta}$, often used to estimate the downwind, lateral dispersion and spread of pollutant plumes, are compared between the wind vane and sonic anemometers. Results shown in Fig. (9) indicate a generally good agreement with the median ratio of vane/sonic equal to 1.02 with $90 \%$ of values between 0.94 and 1.23 across all wind speeds and an $r^{2}$ value of 0.84 . However, there are some cases with the vane indicating $\sigma_{\theta}$ values approaching or reaching zero during very light wind conditions.

The fractional analysis in Fig. (10) better illustrates the dramatic change in the ratio of $\sigma_{\theta}$ values as measured by the wind vane and sonic anemometer. The agreement between the values from the two instruments is good for wind speeds above $2 \mathrm{~ms}^{-1}$, although the vane yields $\sigma_{\theta}$ values that are $7 \%$ greater than those from the sonic. The bias is consistent with the slower response of the wind vane (i.e., vane overshooting). Scatter increases significantly at wind speeds below 2 $\mathrm{ms}^{-1}$ and the relationship between the measurements becomes more complicated at lower speeds. The ratio of vane/sonic $\sigma_{\theta}$ values tends to spike at average wind speeds of

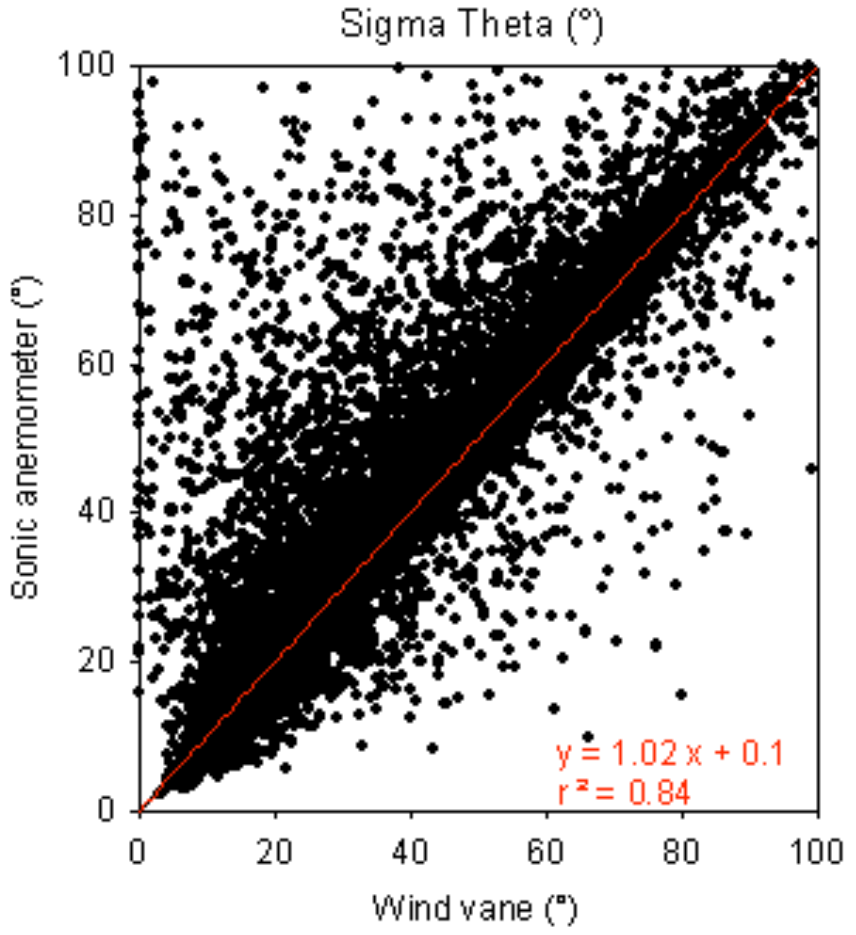

Fig. (9). Regression analysis of 15-minute average $\sigma_{\theta}$ as measured by wind vane $v s$ sonic anemometer.

about $0.5 \mathrm{~ms}^{-1}$ and then plunge as speeds approach the starting thresholds of the vane and cup anemometer. This behavior may result from the less responsive vane yielding excessive variation by overshooting at very light speeds of about $0.5 \mathrm{~ms}^{-1}$ and too little variation as speeds diminish toward or even below the starting threshold of $0.22 \mathrm{~ms}^{-1}$.

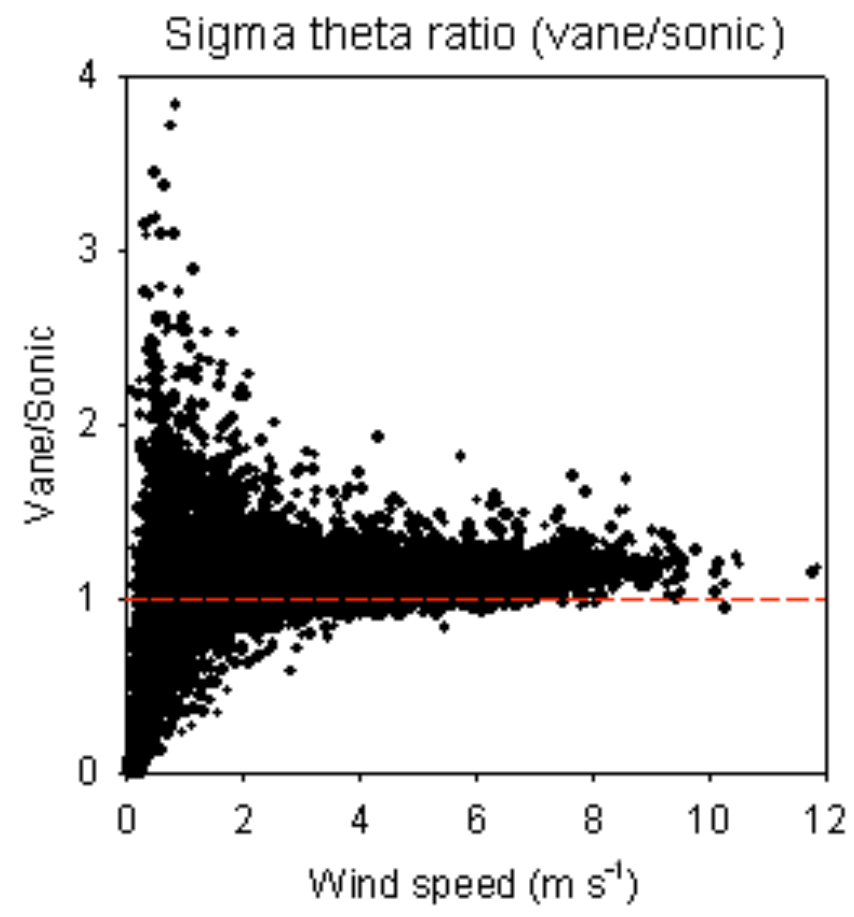

Fig. (10). Ratio of vane/sonic anemometer-derived $\sigma_{\theta}$ as a function of wind speed as measured by the cup anemometer. 


\subsection{Vertical Wind Variables and Parameters}

Median vertical wind speeds for all horizontal wind speeds (not shown) indicate that both the vertical propeller and sonic anemometer indicate virtually no average vertical transport ( 0.02 and $-0.01 \mathrm{~ms}^{-1}$, respectively). The results are consistent with the flat terrain and differences from zero are well within the instrument resolution and possible slight mounting differences from the vertical. The comparison of $\sigma_{w}$ values measured by the vertical propeller and sonic anemometers is shown in Fig. (11). The correlation is excellent with $r^{2}=0.98$. Note that the propeller yields $\sigma_{w}$ values about $0.1 \mathrm{~ms}^{-1}$ lower than the sonic at low values and about $0.1 \mathrm{~ms}^{-1}$ higher than the sonic at higher values. Part of the bias results from the application of the correction factor (1.25) to the propeller for the non-cosine response error: the factor may be too small at low wind speeds and too high at higher wind speeds.

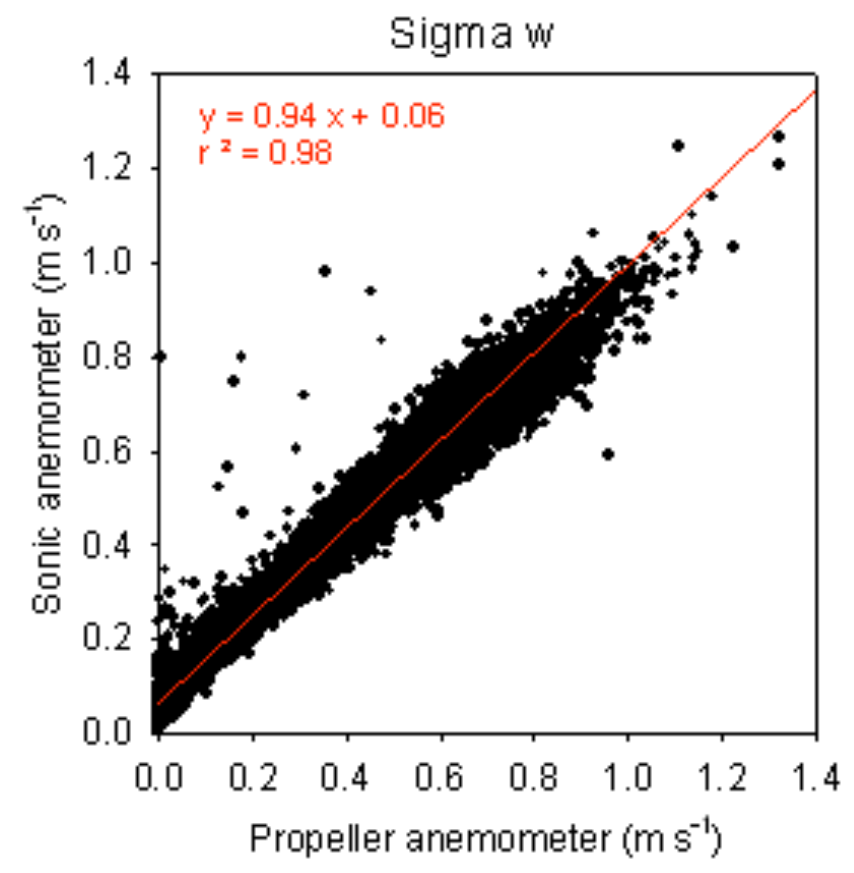

Fig. (11). Regression analysis of 15-minute average $\sigma_{w}$ as measured by vertical propeller $v s$ sonic anemometer.

A fractional analysis of the two measurements describes the differences as a function of horizontal wind speed and is shown in Fig. (12). Similar to some of the horizontal wind variables previously analyzed, the agreement between the mechanical and sonic sensors deteriorates at lower horizontal wind speeds. Because of the vertical orientation of the mechanical propeller, the breakdown in agreement starts occurring at speeds less than $3 \mathrm{~ms}^{-1}$, at a somewhat higher threshold than for the horizontal wind analyses.

The median propeller/sonic ratio for $\sigma_{w}$ values is 0.83 for all wind speeds and it increases to 0.91 for speeds greater than $2 \mathrm{~ms}^{-1}$ and it exceeds 1 for wind speeds exceeding about $5.5 \mathrm{~ms}^{-1}$. The median propeller/sonic ratio decreases to only 0.47 and 0.10 at horizontal wind speeds below 2 and $1 \mathrm{~ms}^{-1}$, respectively. The bias is especially large at wind speeds less

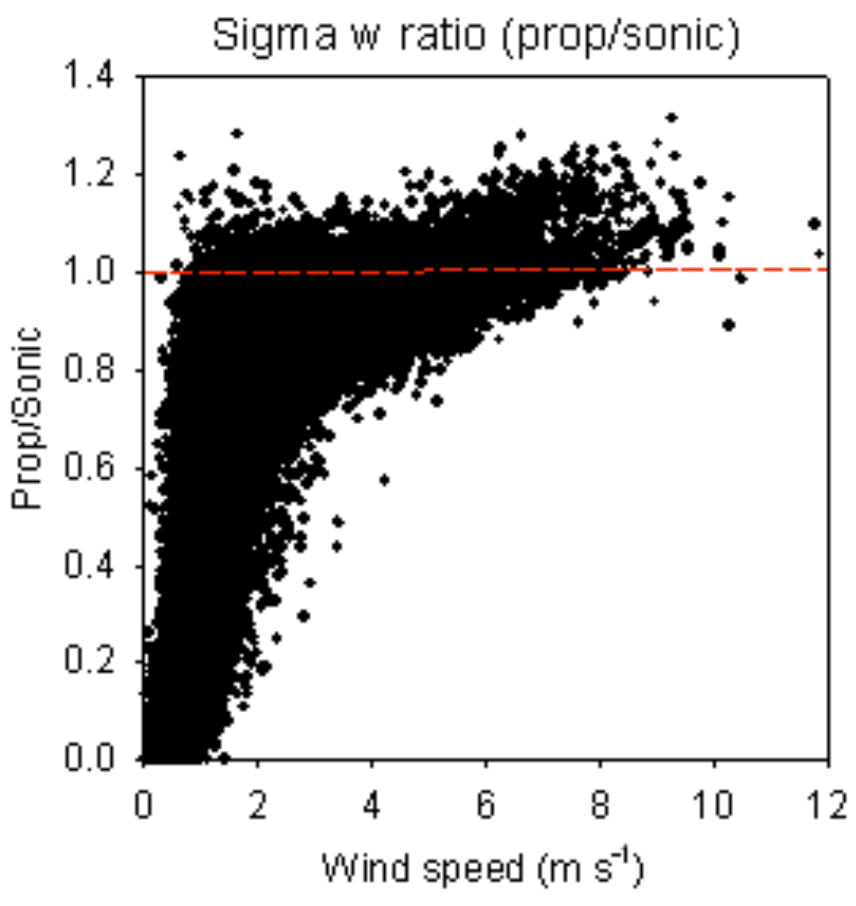

Fig. (12). Ratio of propeller/sonic anemometer-derived $\sigma_{w}$ as a function of wind speed as measured by the cup anemometer.

than $1 \mathrm{~ms}^{-1}$, when the propeller measures $\sigma_{\mathrm{w}}$ values less than $50 \%$ of sonic values about $85 \%$ of the time. The bias results from the poor response of the propeller during stable conditions and light winds. These results are consistent with a study by Garratt [13] that indicates the use of a vertical propeller at a $10-\mathrm{m}$ height above ground during stable conditions will lead to underestimation of vertical velocity fluctuations. Finkelstein et al. [14] suggest that intermittent stalling of the propeller anemometer led to similar underestimation of $\sigma_{w}$ and $\sigma_{\phi}$ during stable conditions with light winds during a field study.

The measured $\sigma_{w}$ and $u$ values can be combined to estimate $\sigma_{\phi}$, often used to estimate vertical dispersion and pollutant spread. A regression analysis of $\sigma_{\phi}$ values estimated from the mechanical sensors and the sonic anemometer (not shown) indicates a rather poor linear correlation with an $r^{2}$ of only 0.56 . The relatively poor correlation is not surprising since $\sigma_{\phi}$ is derived from two separate variables. A fractional analysis of the two $\sigma_{\phi}$ measurements by wind speed is shown in Fig. (13). The bias variation for mechanical/sonic $\sigma_{\phi}$ ratios with wind speeds greater than $3 \mathrm{~ms}^{-1}$ is similar to the $\sigma_{w}$ analysis in Fig. (12): the median cup\&prop/sonic ratio for $\sigma_{\phi}$ values is 0.78 for all wind speeds and it increases to 0.88 for speeds greater than $2 \mathrm{~ms}^{-1}$ and it exceeds 1 for wind speeds exceeding about $6 \mathrm{~ms}^{-1}$. The bias of $\sigma_{\phi}$ values at lower speeds is somewhat worse than for $\sigma_{w}$ : the median cup\&prop/sonic ratio decreases to only 0.42 and 0.08 at horizontal wind speeds below 2 and $1 \mathrm{~ms}^{-1}$, respectively. The bias is especially large at wind speeds less than $1 \mathrm{~ms}^{-1}$, when the propeller-measured $\sigma_{\phi}$ values are less than $50 \%$ of sonic values $90 \%$ of the time. The somewhat greater bias of $\sigma_{\phi}$ relative to 
$\sigma_{w}$ values at low wind speeds results from the contribution of over-speeding by the cup anemometer (i.e., larger $u$ values will cause smaller $\sigma_{\phi}$ values).

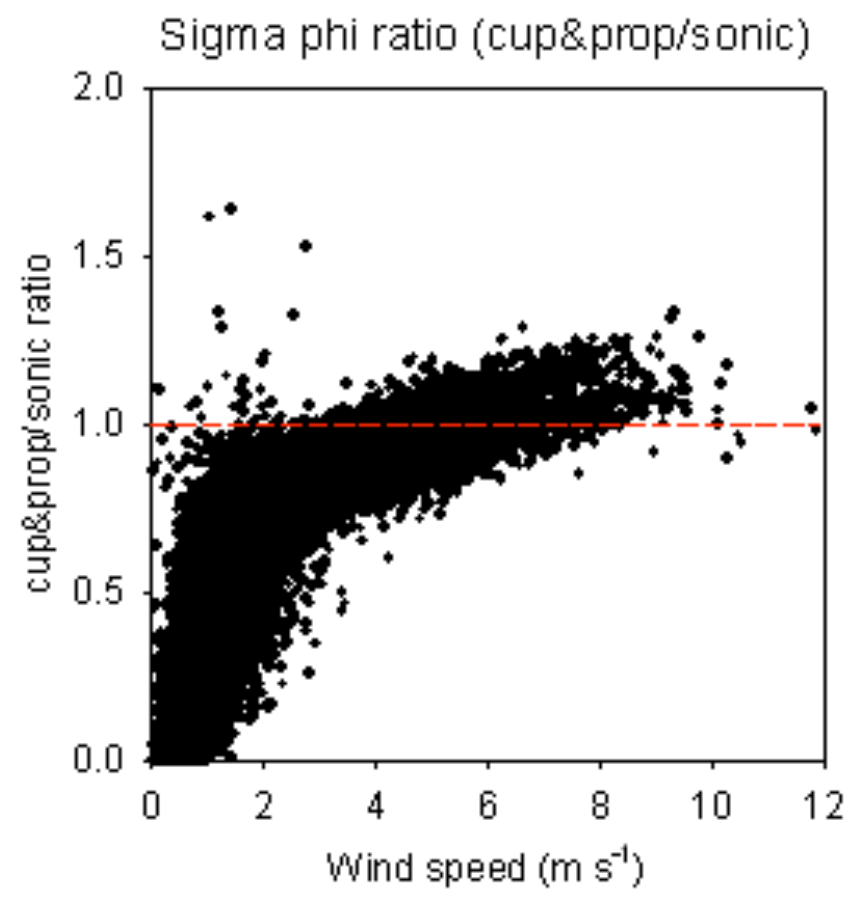

Fig. (13). Ratio of cup\&propeller/sonic anemometer-derived $\sigma_{\phi}$ as a function of wind speed as measured by the cup anemometer.

The average diurnal variation during July (2004) of $u, \sigma_{w}$, and $\sigma_{\phi}$ shown in Fig. (14) illustrates further the differences between the sonic and the mechanical sensors as well as the variation in wind speed and vertical turbulent parameters. Skies were clear during most if not the entire month as is typical during summer months in the region (not shown). Wind speed reaches a maximum during late afternoon as a result of deep thermal instability and frequent occurrence of sea breezes. Note that the cup anemometer shows slightly higher wind speeds than the sonic as it tends to over speed during very light wind. The differences in $\sigma_{w}$ measurements are noticeable in the early morning as the propeller underestimates by almost $25 \%$ on average. The underestimation becomes greater (or less) during periods with lower (or higher) than average wind speeds. The $\sigma_{w}$ values as measured by the propeller abruptly approach those measured by the sonic shortly after sunrise until early evening, when the propeller again indicates lower values. The largest differences in measurements can be seen with $\sigma_{\phi}$ as the estimates derived from mechanical sensors underestimate by about $50 \%$ on average during early morning compared to the sonic. While the underestimation is reduced after sunrise, $\sigma_{\phi}$ values derived from mechanical sensors don't approach those from the sonic until almost noon. The bias in $\sigma_{\phi}$ reappears during the evening.

Momentum flux values were also calculated by calculating covariances of 1 -second measurements of $u$ and $w\left(-\overline{u^{\prime} w}\right)$ using the cup anemometer with the propeller
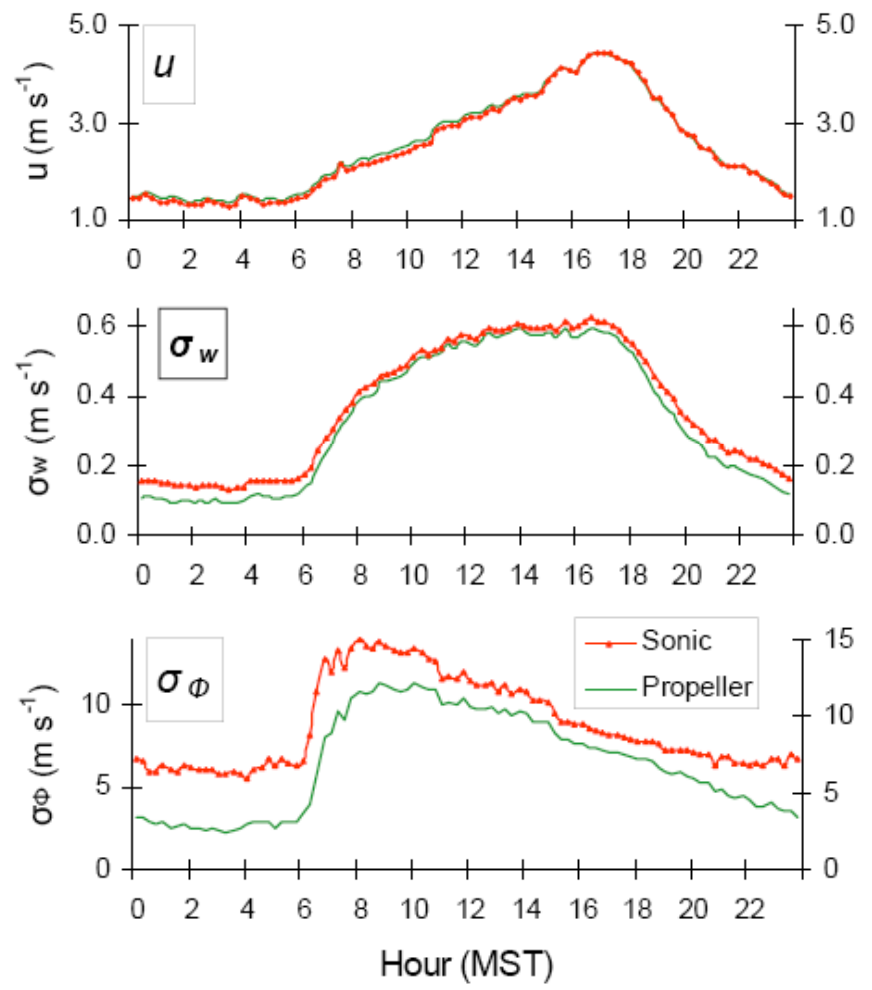

Fig. (14). Averaged 15-minute values of $u, \sigma_{w}$, and $\sigma_{\phi}$ measured by the sonic anemometer and mechanical sensors (cup and propeller anemometers) during July 2004. The average sunrise and sunset times were approximately 05:00 and 19:30 MST respectively.

anemometer and using the $u$ and $w$ components measured by the sonic anemometer. The scatter plot is shown in Fig. (15). Note that positive values indicate downward transport and negative values indicate upward transport of momentum. The correlation is excellent $\left(r^{2}=0.86\right)$ especially considering that two instruments contribute to $-\overline{u^{\prime} w}$. The regression line indicates that the mechanical sensors tend to yield absolute values approximately $15 \%$ more than from the sonic anemometer for larger positive and negative (upward and downward) values. A fractional analysis by wind speed (not shown) indicates that the median ratio of cup\&propeller/ sonic ratios of $-\overline{u^{\prime} w}$ values decreases from 0.74 for all speeds to 0.42 at less than $2 \mathrm{~ms}^{-1}$ and close to 0 for speeds less than $1 \mathrm{~ms}^{-1}$. These results once again point out that the mechanical sensors lack the responsiveness necessary to provide good results at very light wind speeds. The summary of results for wind and turbulent parameters is included in Table 2.

\section{CONCLUSIONS}

The low-cost 3-D anemometer reliably measured the three components of wind during an entire year during this study. Data from the sonic anemometer and mechanical wind sensors were analyzed and compared. Results indicate that 15-minute averaged horizontal wind variables (wind speed or $u, \sigma_{u}$, wind direction $[\theta]$, and $\sigma_{\theta}$ ) and peak wind gusts measured by mechanical sensors agree well with those measured by an inexpensive 3-D sonic anemometer for wind speeds above 2 to $2.5 \mathrm{~ms}^{-1}$. The mechanical sensors (cup 


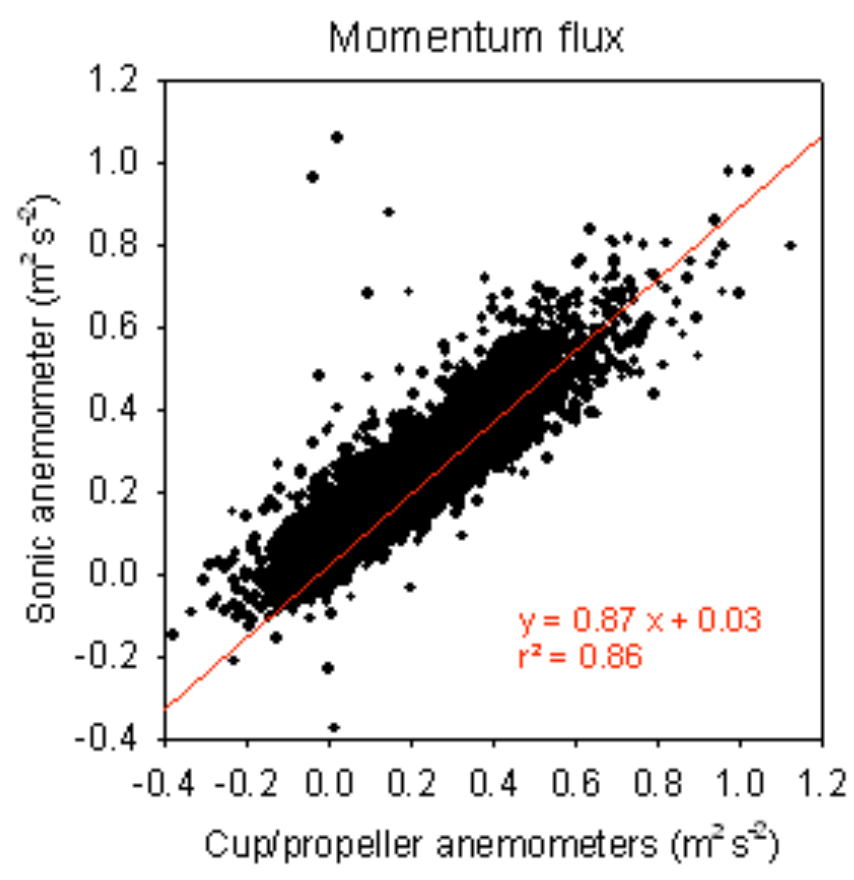

Fig. (15). Regression analysis of 15-minute average $-\bar{u} w$ as measured by cup anemometer and vertical propeller $v s$ sonic anemometer.

anemometer and wind vane) typically produce $\sigma_{u}$ and $\sigma_{\theta}$ values about 5\% lower and higher, respectively, than from the sonic anemometer at these higher speeds. The agreement between measured vertical wind variables and parameters $\left(w, \sigma_{w}, \sigma_{\phi}\right.$, and $-\overline{u^{\prime} w}$ ) was also very good above a slightly higher threshold of $3 \mathrm{~ms}^{-1}$ or so. The vertical propeller typically measures $\sigma_{w}$ and $\sigma_{\phi}$ values about $10 \%$ lower than the sonic anemometer with wind speeds of 2.5 to $4 \mathrm{~ms}^{-1}$ and about $10 \%$ higher at wind speeds above about $6.5 \mathrm{~ms}^{-1}$.

The advantage of the sonic anemometer becomes increasingly obvious as winds become light and the mechanical sensors become less responsive. The cup anemometer produces values that increasingly overestimate $u$ and $\sigma_{u}$ compared to the sonic anemometer on a fractional basis as wind speed decreases below $2 \mathrm{~ms}^{-1}$. The difference in wind direction between the vane and sonic measurements becomes large at speeds below $1 \mathrm{~ms}^{-1}$; however, it is difficult to determine the contribution from inadequate wind vane response. The effect of inadequate vane response on $\sigma_{\theta}$ measurements is more complicated as the vane increasingly overestimates on a percentage basis as horizontal wind speeds decrease below $2.5 \mathrm{~ms}^{-1}$, reaching a maximum at about a 0.5 $\mathrm{ms}^{-1}$ wind speed before it underestimates as speeds approach calm.

The most significant differences are associated with the standard deviation of vertical wind fluctuations $\left(\sigma_{w}\right)$ : the colocated vertical propeller anemometer yields values increasingly less than those measured by the sonic anemometer as horizontal wind speeds decrease from 2.5 to near $0 \mathrm{~ms}^{-1}$. The underestimation of $\sigma_{w}$ by the vertical propeller and to a lesser extent overestimation of $u$ by the cups at low wind speeds compounds the errors for the standard deviation of vertical wind angle fluctuations, $\sigma_{\phi}$, an indicator of vertical dispersion that is often used to calculate the Pasquill-Gifford (P-G) stability category. The sonic anemometer routinely indicates larger $\sigma_{\phi}$ values than the vertical propeller/cup anemometer with the sonic anemometer values typically $5^{\circ}$ to $10^{\circ}$ higher when the propeller/cup indicate $\sigma_{\phi}$ is less than about $5^{\circ}$. The errors in the mechanical sensors, caused by their inability to capture the higher frequency (smallest scale) turbulent fluctuations, could therefore lead to large (factors of 2 to 10 or more) errors in both vertical and horizontal dispersion estimates during stable conditions with light winds. The sonic anemometer also provides more reliable momentum flux data during light winds.

This low cost sonic anemometer is ideally suited to supplement or even replace routine wind measurements made by traditional mechanical sensors assuming that a local AC power source is available. The sonic anemometer is superior to and more accurate than mechanical sensors with wind speeds less than $2.5 \mathrm{~ms}^{-1}$. The value of the sonic anemometer is especially great at this and other sites which experience

Table 2. Summary of Mechanical Sensor to Sonic Anemometer Comparisons for Wind and Turbulent Parameters

\begin{tabular}{|c|c|c|c|c|c|}
\hline Peak wind gust & 0.922 & 1.02 & 1.00 & 1.07 & 1.12 \\
\hline $\operatorname{Sigma} u\left(\sigma_{u}\right)$ & 0.98 & 0.95 & 0.94 & 0.98 & 1.08 \\
\hline $\operatorname{Sigma} w\left(\sigma_{w}\right)$ & 0.98 & 0.83 & 0.91 & 0.47 & 0.10 \\
\hline Sigma phi $\left(\sigma_{\phi}\right)$ & 0.56 & 0.78 & 0.88 & 0.42 & 0.08 \\
\hline Momentum flux $\left(-\overline{u^{\prime} w^{\prime}}\right)$ & 0.86 & 0.74 & 0.89 & 0.02 & 0.00 \\
\hline
\end{tabular}


frequent light winds. At the same time, the 3-D sonic anemometer requires little or no maintenance, thereby making it much easier to support and less expensive to operate compared to mechanical sensors.

\section{ACKNOWLEDGEMENTS}

The author thanks Art Biermann and Gretchen Gallegos for their support for the meteorological monitoring program and Gary Bear for his effort in maintaining and improving the meteorological monitoring. The author also thanks Dennis Lundy of Western Weather Group, LLC for setting up the sonic anemometer and its data collection. The helpful comments by Charlene Grandfield and the anonymous reviewers are greatly appreciated.

This work was performed under the auspices of the U.S. Department of Energy by Lawrence Livermore National Laboratory in part under Contract W-7405-Eng-48 and in part under Contract DE-AC52-07NA27344.

\section{REFERENCES}

[1] Coppin PA, Taylor KJ. A three-component sonic anemometer/thermometer system for general micrometeorological research. Boundary Layer Meteorol 1983; 27: 27-42.

[2] Wieser A, Fiedler F, Corrsmeier U. The influence of the sensor design on wind measurements with sonic anemometer systems. J Atmos Oceanic Technol 2001; 18: 1585-1608.

[3] Lewis R, Dover JM. Field and operational tests of a sonic anemometer for the automated surface observing system. $8^{\text {th }}$ Symp. on Integrated Observing and Assimilation Systems for Atmosphere, Oceans, and Land Surface, Seattle, WA, Amer Meteor Soc 2004; CD-ROM, 7.1.
[4] Wastrack KG, Pittman DE, Hamberger LW. Wind sensor comparison-ultrasonic versus wind vane/anemometer. $11^{\text {th }}$ Symp. on Meteorological Observations and Measurements, Albuquerque, NM, Amer Meteor Soc 2001; 29-34.

[5] Baxter RA, Yoho DL, Durkee KR. Quality assurance audit program for surface and upper-air meteorological measurements in the south coast air basin in California. $12^{\text {th }}$ Symp. on Meteorological Observations and Measurements, Long Beach, CA, Amer. Meteor. Soc., 2003; CD-ROM, 6.5.

[6] Vidal E, Yee Y. Data collection of high resolution 3D sonic anemometer measurements; 19th International Conference on Interactive Information Processing Systems (IIPS) for Meteorology, Oceanography, and Hydrology, Long Beach, CA, Amer Meteor Soc 2003; P1.5.

[7] Gouveia FJ, Chapman KR. Climatology of Lawrence Livermore National Laboratory, UCID-21686, Lawrence Livermore National Laboratory, Livermore, CA. 1989.

[8] Yamartino RJ. A comparison of several "single-pass" estimators of the standard deviation of wind direction. J Climate Appl Meteor 1984; 23: 1362-66.

[9] Wyngaard JC. Cup, propeller, and sonic anemometers in turbulence research. Ann Rev Fluid Mech 1981; 13: 399-423.

[10] Gilhousen DB. An evaluation of Gill sonic anemometers in the marine environment; $11^{\text {th }}$ Symp. on Meteorological Observations and Measurements, Albuquerque, NM, Amer Meteor Soc 2001; 35 39.

[11] Anfossi D, Oettl D, Degrazia G, Goulart A. An analysis of sonic anemometer observations in low wind speed conditions. Boundary Layer Meteorol 2005; 114: 179-203.

[12] Deaves DM, Lines IG. The nature and frequency of low wind speed conditions. J Wind Eng Ind Aerodyn 1998 ; 73: 1-29.

[13] Garratt JR. Limitations of the eddy-correlation technique for the determination of turbulent fluxes near the surface. Boundary Layer Meteorol 1975; 8: 255-59.

[14] Finkelstein PL, Kaimal JC, Gaynor JE, Graves ME, Lockhart TJ. Comparison of wind monitoring systems. Part I: In situ sensors. J Atmos Oceanic Technol 1986; 3: 583-93. 